\title{
ADHD in DSM-5: a field trial in a large, representative sample of 18- to 19-year-old adults
}

\author{
B. Matte ${ }^{1}$, L. Anselmi ${ }^{1,2}$, G. A. Salum ${ }^{1,3}$, C. Kieling ${ }^{1,3}$, H. Gonçalves ${ }^{2}$, A. Menezes ${ }^{2}$, E. H. Grevet ${ }^{1}$ \\ and L. A. Rohde ${ }^{* 1,3}$ \\ ${ }^{1}$ ADHD Out-patient Program, Hospital de Clinicas de Porto Alegre, Department of Psychiatry, Federal University of Rio Grande do Sul, Brazil \\ ${ }^{2}$ Post-Graduate Program in Epidemiology, Federal University of Pelotas, Brazil \\ ${ }^{3}$ National Institute of Developmental Psychiatry for Children and Adolescents, São Paulo, Brazil
}

\begin{abstract}
Background. The DSM criteria for adult attention-deficit/hyperactivity disorder (ADHD) have not been tested in American Psychiatric Association (APA) field trials for either DSM-IV or DSM-5. This study aimed to assess: (a) the prevalence of ADHD according to DSM-5 criteria; $(b)$ the factor solution that provides the best fit for ADHD symptoms; (c) the symptoms with the highest predictive value for clinical impairment; and (d) the best symptomatic threshold for each ADHD dimension (inattention and hyperactivity/impulsivity).
\end{abstract}

\begin{abstract}
Method. Trained psychologists evaluated 4000 young adults from the 1993 Pelotas Birth Cohort Study with an instrument covering all DSM-5 ADHD criteria. A series of confirmatory factor analyses (CFAs) tested the best factor structure. Complex logistic regressions assessed differential contributions of each symptom to clinical impairment. Receiver-operating characteristic (ROC) analyses tested which would be the best symptomatic cut-off in the number of symptoms for predicting impairment.

Results. The prevalence of DSM-5 ADHD was 3.55\% [95\% confidence interval (CI) 2.98-4.12]. The estimated prevalence of DSM-IV ADHD was $2.8 \%$. CFA revealed that a bifactor model with a single general factor and two specific factors provided the best fit for DSM-5 symptoms. Inattentive symptoms continued to be the most important predictors of impairment in adults. The best cut-offs were five symptoms of inattention and four symptoms of hyperactivity/ impulsivity.

Conclusions. Our results, combined with previous findings, suggest a $27 \%$ increase in the expected prevalence of ADHD among young adults, comparing DSM-IV to DSM-5 criteria. The DSM-5 symptomatic organization derived a similar factor structure for adults as DSM-IV symptoms. Data using DSM-5 criteria support lowering the symptomatic threshold for diagnosing ADHD in adults.
\end{abstract}

Received 20 November 2013; Revised 17 May 2014; Accepted 24 May 2014; First published online 23 June 2014

Key words: ADHD, diagnostic performance, DSM-5, epidemiology, prevalence.

\section{Introduction}

Attention-deficit/hyperactivity disorder (ADHD) is a neurodevelopmental disorder characterized by pervasive and persistent symptoms of inattention, hyperactivity and impulsivity, affecting individuals across the life cycle (Matte et al. 2012). Research and clinical data have documented that a significant proportion of children affected by the disorder continues to present ADHD symptoms and associated impairment during adulthood (Faraone et al. 2006; Barkley, 2010; Das et al. 2012). The two most comprehensive estimates of

* Address for correspondence: L. A. Rohde, M.D., Ph.D., Programa de Transtorno de Déficit de Atenção/Hiperatividade, Hospital de Clínicas de Porto Alegre, Rua Ramiro Barcelos 2350, Porto Alegre, Rio Grande do Sul, Brazil.

(Email: lrohde@terra.com.br)
ADHD prevalence in adults suggest prevalence rates between $2.5 \%$ and $3.4 \%$ (Fayyad et al. 2007; Simon et al. 2009).

The diagnostic criteria for ADHD were not tested in adults in the field trials for DSM-IV (Matte et al. 2012), and ADHD was not among the disorders assessed in DSM-5 field trials in adults (Batstra \& Frances, 2012). The DSM-5 criteria for ADHD kept the bidimensional structure of ADHD and the same list of symptoms, but proposed modifications that might impact on the ADHD diagnostic definition for adults, including: (a) a reduction in the number of required symptoms (cut-off point) in both ADHD dimensions (inattention and hyperactivity/impulsivity) from six to five in adults; (b) raising the age at onset from 7 to 12 years, and removing the requirement of impairment from this criterion; and $(c)$ the addition of new clinical examples for symptoms. DSM-5 also proposed 
modifications that are relevant for all age ranges, such as defining pervasiveness as the presence of several ADHD symptoms (instead of impairment) in two or more settings, and the removal of autism/pervasive developmental disorder (PDD) as a specific exclusion (for a more comprehensive discussion on the rationale for these modifications, see Matte et al. 2012). These proposed changes in ADHD diagnostic criteria raised major concerns about potentially negative consequences, such as inflating prevalence rates of the disorder, overdiagnosis and overtreatment (Regier et al. 2013).

There are no epidemiological studies with nonreferred subjects testing DSM-5 proposed changes. These studies are crucial for a proper evaluation of the prevalence rates and the natural distribution of the ADHD phenotype in the general population (Goodman et al. 1997). Additionally, information about how the specific diagnostic criteria impact on ADHD prevalence would be clinically useful, considering that ADHD is best conceptualized as a dimensional disorder (Willcutt et al. 2012). The performance of individual symptoms is even more relevant, considering that clinicians often match the patient's symptoms against a prototype based on some but not all diagnostic criteria, rather than using full DSM operational diagnostic criteria for making diagnoses (Maj, 2011; Jablensky, 2012).

Thus, our main objective was to assess the prevalence of ADHD according to DSM-5 criteria in a large, non-referred, representative population of young adults. We also addressed the individual impact of new criteria (such as the extension of the age of onset to 12 years and lower symptom cut-offs) on ADHD prevalence rates. In addition, because DSM-5 criteria displayed some rewording and new clinical examples for ADHD symptoms in adults, we also tested: (a) the factorial solution that provides the best fit for the DSM-5 ADHD symptoms, $(b)$ the association of DSM-5 ADHD symptoms with clinical impairment, and $(c)$ the best number (cut-off point) of DSM-5 ADHD symptoms to identify impaired adults in both ADHD dimensions.

\section{Method \\ Participants}

Participants in this study were young adults followed in the 1993 Pelotas Birth Cohort Study. Pelotas is a southern Brazilian city with around 327000 inhabitants. A full description of the methodology is presented elsewhere (Victora et al. 2008). In brief, all 5249 live births in the city in 1993 whose mothers agreed to participate in the longitudinal study were considered eligible. The data used in this study were collected in 2011-2012, when the subjects were 18-19 years old. This follow-up assessment comprised all subjects who were located among the initial participants. The Institutional Review Board of the Federal University of Pelotas approved the study. Written informed consent was obtained from all subjects.

\section{Measures}

Trained psychologists performed the entire diagnostic evaluation with the subjects. A general psychiatric assessment was performed with the Mini International Neuropsychiatric Interview (MINI), a short semistructured diagnostic interview for DSM-IV and ICD-10 psychiatric disorders that provided prevalence estimates of common mental disorders. Because of logistic issues (i.e. the psychiatric interview was part of a larger follow-up assessment), only some MINI sections were performed. The most prevalent mood (major depression and bipolar) and anxiety (agoraphobia, social phobia, general anxiety) disorders were assessed. The MINI has a previously validated Portuguese version (Amorim, 2003). In primary health care in Brazil, the MINI exhibited $\kappa$ values of $0.65-0.85$, a sensitivity of $0.75-0.92$ and a specificity of 0.90-0.99 when using the SCID applied by a psychiatrist as a parameter (Marques \& Zuardi, 2008). Sociodemographic variables were collected at the same interview.

The ADHD assessment was performed with a structured interview that included 18 questions about DSM-5 ADHD symptoms (one question for each symptom). These questions were formulated exactly as proposed by the DSM-5 ADHD working group and were freely available during 2011 and 2012 at www.dsm5. org. Thus, we present here the performance of the current DSM-5 diagnostic criteria for ADHD (APA, 2013). DSM-5 defines ADHD in adults as the presence of at least five of nine symptoms of inattention and/or five of nine symptoms of hyperactivity/impulsivity. ADHD symptoms must cause clinical impairment, several of them must be present in more than one setting, and their age at onset should be before age 12 years.

The DSM-5 ADHD symptoms were rated as present or absent. Considering that this was a large population study, we initially applied a screening questionnaire using the same structure as the World Health Organization Adult ADHD Self-Report Scale (ASRS) screener for all subjects. The ASRS includes six questions about ADHD symptoms (four inattention items: 'Does not follow through', 'Difficulty organizing tasks', 'Forgetful', 'Reluctant to engage in "mental" tasks'; and two hyperactivity items: 'Fidgets' and 'On the $\left.\mathrm{go}^{\prime}\right)$. In a previous population study, the ASRS 
had $68.7 \%$ sensitivity, $99.5 \%$ specificity and $97.9 \%$ total classification accuracy, considering blind clinical assessment as the gold standard and using a cut-off of $4 / 6$ screening symptoms (Kessler et al. 2005). In our questionnaire, those six ASRS questions were adapted to the exact DSM-5 wording. To enhance sensitivity, any subject with two or more positive questions among the six was considered screening positive, and answered 12 additional questions about the 12 remaining ADHD symptoms, along with other questions about additional criteria (symptom pervasiveness, age at onset before 12 years old, and clinical impairment). To assess symptom pervasiveness, subjects were asked if they presented symptoms in at least two of the three main settings: home, social and work/school environments. To assess the presence of ADHD symptoms before age 12, we asked 'Did you have several of these symptoms before age 12?' Clinical impairment specifically related to ADHD was measured using a question answered by the subjects at the end of the ADHD section of the assessment interview. The question asked was: 'How much impairment your ADHD symptoms cause to your life?' The options for answer were: none (0), mild impairment (1), moderate impairment (2), or severe impairment (3). For the current analyses, the presence of clinical impairment was operationally defined as having a score of 2 (moderate) or 3 (severe).

This strategy for assessing impairment was chosen to mimic approaches in clinical settings, in which clinicians tend to rely on the subject's general perception of impairment instead of on extensive evaluations of correlates of functioning. Thus, clinicians tend to assess ADHD impairment based on patient's perceptions (Rösler et al. 2006). Although the threshold for defining impairment is subjective and individual, clinicians diagnose ADHD even in cases without substantial impairment. Thus, the threshold of self-report moderate impairment tends to be conservative.

\section{Data analytic strategy: description of the sample}

Sociodemographic and co-morbidity patterns were assessed both for DSM-5 ADHD cases and for subjects without ADHD. These two groups were compared using appropriate univariate tests.

\section{Assessment of ADHD prevalence and exploration of the impact of individual diagnostic criteria on ADHD prevalence rates}

The consequences of using different symptom thresholds on ADHD prevalence rates were explored by calculating the proportion of subjects that would be defined as ADHD cases according to several potential symptomatic cut-offs. We also applied the ADHD additional criteria consecutively to examine their individual impact on ADHD prevalence rates. For these prevalence assessments, we used data from the entire sample; the subjects who screened negative for ADHD (less than two out of six positive screening questions) were assumed to be negative for ADHD. Moreover, we estimated a comparison between DSM-IV and DSM-5 ADHD prevalence in our sample. This was an indirect comparison because we could not assess either ADHD symptoms with DSM-IV wording or the presence of impairment of symptoms before 7 years (as DSM-IV required). To derive an ADHD diagnosis according to DSM-IV criteria, we considered data from this sample using the 6/9 cut-point proposed by DSM-IV. To deal with age-of-onset criterion modification while avoiding the effect of recall bias in a crosssectional study asking for the exact date of beginning ADHD symptoms, we relied on a previous study documenting an increase of $0.1 \%$ in ADHD prevalence rates with this DSM criterion B modification. It is important to note that this rate was obtained in a longitudinal assessment (Polanczyk et al. 2010). Thus, we estimated the DSM-IV prevalence in this sample as the ADHD prevalence for the 6/9 cut-point with an additional $0.1 \%$ discount.

\section{Assessment of the factor solution that provides the best fit for ADHD symptoms}

The factor structure of the 18 DSM-5 ADHD symptoms was tested with confirmatory factor analysis (CFA) in the subsample that screened positive for ADHD (at least $2 / 6$ positive screening questions) and completed the entire ADHD assessment. Several CFA models were fitted to the data: $(a)$ a one-factor model; $(b)$ a correlated two-factor model; $(c)$ a correlated three-factor model; (d) a second-order two-factor model; (e) a second-order three-factor model; $(f)$ a bifactor model with one general and two specific factors; $(g)$ a bifactor model with one general and three specific factors; and (h) an incomplete bifactor model with one general and two specific factors (in this model the hyperactivity factor is suppressed as all hyperactivity symptoms are explained by the general ADHD factor). This strategy allowed us to determine which factor solution provided the best fit for DSM-5 ADHD symptoms. CFA models were fitted to polychoric correlations among the symptoms using the weighted least squares means and variance adjusted (WLSMV) estimator implemented in Mplus 7.0 (Muthén \& Muthén, 2012). The goodness of fit was assessed using the following fit indices: $\chi^{2}$, the weighted root mean square residual (WRMR), the Comparative Fit Index (CFI), the TuckerLewis Index (TLI) and the root mean square error of approximation (RMSEA). To demonstrate good fit 
to the data, an estimated model should have a WRMR $\leqslant 0.9$ (Muthén \& Muthén, 2012), RMSEA $\leqslant 0.06$ and CFI and TLI $\geqslant 0.95$ (Hu \& Bentler, 1999). We compared nested models directly using the robust chi-square difference test with mean and variance adjusted test statistics (Asparouhov \& Muthén, 2006). We also provided the differences between models with regard to Akaike information criterion $(\triangle \mathrm{AIC})$ and Bayesian information criterion $(\triangle \mathrm{BIC})$, using the robust maximum likelihood estimator (MLE). Lower values for AIC and BIC indicate a better fit. Values of $\triangle \mathrm{AIC}$ and $\triangle \mathrm{BIC} \leqslant 10$ indicate overwhelming support for the models with lower values (Burnham, 2004). To reduce the number of statistical comparisons, we first identified the best models within the correlated models (including the unidimensional model), the bifactor models and the second-order models. We then compared the best models from each kind of factor structure.

\section{Assessment of the association of ADHD symptoms with clinical impairment}

A three-step approach was implemented to examine which individual DSM-5 ADHD symptoms are the best predictors of moderate to severe clinical impairment. These analyses were also performed only in the subsample that screened positive for ADHD. First, the bivariate association between symptoms and clinical impairment was assessed with the $\chi^{2}$ test and unadjusted odds ratio (OR) estimates, which allowed ranking the DSM-5 symptoms according to their OR related to clinical impairment. Second, a binary stepwise logistic regression model was performed, considering clinical impairment as the dependent variable and all DSM-5 ADHD symptoms as independent variables. This analysis depicted how many, and which, DSM-5 symptoms were independently associated with clinical impairment after controlling for the other DSM-5 symptoms. Third, all-possible-subsets (APS) logistic regression analysis was used to confirm the set of DSM-5 symptoms that best predicted clinical impairment. The APS analysis helped to select the best subset from a larger set of predictors. In such situations, different subsets might have almost equivalent associations with the outcome, and conventional stepwise regression analysis might select a suboptimal subset because of minor differences in bivariate associations. The APS analysis avoids this problem as it generates results for a large number of different models with a fixed number of predictors, which were determined by the earlier stepwise logistic regression analysis. The APS analysis also ranks the best subsets according to their association with the outcome (using $\chi^{2}$ values as ranking criteria). Once the ranking of subsets is known, the researcher can select the predictors that are more consistent across the top-ranked subsets. In our APS analyses, we followed the procedures of Kessler et al. (2010) but used clinical impairment as the dependent variable instead of ADHD diagnosis.

\section{Assessment of the best number of ADHD symptoms (cut-off point) to identify clinical impairment}

Receiver-operating characteristic (ROC) analyses tested which would be the best cut-off (i.e. the best balance between sensitivity and specificity assuming an equal chance of false-positive and false-negative errors in selecting the optimal cut-point) for the number of DSM-5 ADHD symptoms to predict clinical impairment, for both inattention and hyperactivity/ impulsivity dimensions. For these analyses, we initially assumed that those with no positive symptom among the six screening symptoms would be negative for the remaining 12 symptoms. To test this assumption, we simulated the performance of the screening questions in a real dataset that had all the 18 symptoms without any skipping rule for a sample of children from the same Brazilian region $(n=1255$; 6-12-yearolds) (Salum et al. unpublished observations). For children with no positive symptoms in the questions that were part of the screening instrument, the vast majority $(86.9 \%)$ had no additional symptoms. Thus, we included subjects with no positive symptoms in the screening instrument in our first set of ROC analyses. However, we did not include subjects with one positive symptom among the six screening items in this first set of analyses because predictions of the number of other positive symptoms and impairment from the symptoms would be impossible. Next, we performed the same analyses only in the ADHD screening positive subsample.

For all analyses, a 5\% significance level for twotailed test was adopted, unless stated otherwise. The analyses were performed in SAS version 9.0 (APS analysis), Signal Detection Software ROC4 (ROC analyses), Mplus version 7.0 (CFA) and IBM SPSS version 20 (other analyses).

\section{Results}

\section{Description of the sample}

All subjects were in the age range between 18 and 19 years at the time of the interview. A total of 4106 cohort members were located $(81.4 \%$ of the initial sample), and 4000 subjects provided information on ADHD, co-morbidities and sociodemographics. Of these, 1329 subjects (33.2\% of this study sample) screened positive for ADHD and provided information 
Table 1. Sociodemographics and co-morbidity profile of DSM-5 ADHD cases and subjects without ADHD ( $n=4000)$

\begin{tabular}{|c|c|c|}
\hline & Subjects without ADHD & ADHD cases ${ }^{\mathrm{a}}$ \\
\hline$n(\%)$ & 3858 & $142(3.55)$ \\
\hline \multicolumn{3}{|l|}{ Gender (\%) } \\
\hline Male & $49.10^{\mathrm{b}}$ & $39.40^{\mathrm{b}}$ \\
\hline \multicolumn{3}{|l|}{ Self-reported skin color (\%) } \\
\hline White & 64.10 & 59.30 \\
\hline Black & 14.50 & 16.30 \\
\hline Brown & 17.60 & 23.00 \\
\hline Other (Indigenous Brazilian/Asian) & $3.70^{\mathrm{b}}$ & $1.50^{\mathrm{b}}$ \\
\hline \multicolumn{3}{|l|}{ Marital status (\%) } \\
\hline Living with partner & 10.90 & 14.30 \\
\hline \multicolumn{3}{|l|}{ Academic achievement } \\
\hline Years of schooling (mean \pm S.D.) & $8.63 \pm 2.29$ & $7.96 \pm 2.30$ \\
\hline \multicolumn{3}{|l|}{ ADHD presentation $(\%)$} \\
\hline Inattentive & N.A. & 46.50 \\
\hline Hyperactive/impulsive & N.A. & 12.70 \\
\hline Combined & N.A. & 40.80 \\
\hline \multicolumn{3}{|c|}{ Impairment related to ADHD symptoms (\%) } \\
\hline Moderate impairment & N.A. & 60.60 \\
\hline Severe impairment & N.A. & 39.40 \\
\hline \multicolumn{3}{|l|}{ Co-morbidities (\%) } \\
\hline Major depressive disorder & 3.97 & 6.34 \\
\hline Bipolar disorder & 1.74 & 2.82 \\
\hline Anxiety disorders & 39.70 & 37.6 \\
\hline
\end{tabular}

ADHD, Attention-deficit/hyperactivity disorder; N.A., not applicable; S.D., standard deviation.

${ }^{a}$ ADHD cases are subjects with at least five of nine inattention and/or five of nine hyperactivity symptoms + symptom onset before age $12+$ symptoms in more than one setting+moderate or severe impairment related to ADHD symptoms.

${ }^{\mathrm{b}}$ Statistical difference between ADHD and non-ADHD groups $(p<0.05)$. For the 66 ADHD subjects with inattentive presentation, mean \pm S.D. of number of hyperactivity/impulsivity symptoms was $2.65 \pm 1.2$. For the 18 ADHD subjects with hyperactive/impulsive presentation, mean \pm S.D. of number of inattention symptoms was $3.22 \pm 0.9$.

about all ADHD criteria. Sociodemographic and co-morbidity profiles for ADHD cases and subjects without ADHD are shown in Table 1.

\section{Assessment of ADHD prevalence and exploration of the impact of individual diagnostic criteria on ADHD prevalence rates}

According to full DSM-5 criteria, the prevalence of ADHD was $3.55 \%$ [95\% confidence interval (CI) 2.98-4.12]. The prevalence of inattentive, hyperactive/ impulsive and combined presentations was 1.65, 0.45 and $1.45 \%$ respectively. The effects on ADHD prevalence rates of using different symptom cut-off points for assigning a diagnosis are displayed in Table 2. This table also shows the impact on prevalence rates of sequentially applying the ADHD additional criteria. In general, the most significant decrease in ADHD prevalence was determined by age-at-onset criterion, which had a larger effect on prevalence rates than the symptom cut-off or the impairment criteria. Note that ADHD prevalence rates had overlapping CIs with four, five or six symptom cut-offs (Table 2). If severe (rather than at least moderate) clinical impairment was used as an ADHD additional criterion, the prevalence of ADHD would be $1.4 \%$ (95\% CI $1.04-1.76 \%$ ). The ADHD prevalence rate with at least six symptoms in any dimension was estimated to be $2.9 \%$ (95\% CI 2.38-3.42\%) in our sample (Table 2). Discounting the impact of the modification of ageat-onset criterion estimated at $0.1 \%$, we would end up with a DSM-IV ADHD prevalence rate of about $2.8 \%$. We also ran secondary analyses comparing the three groups (subjects without ADHD, ADHD cases based on both DSM-IV and DSM-5, and new ADHD cases based only on DSM-5 criteria) with regard to male/ female ratio, impairment and co-morbidity. There are no differences between the two groups of cases on impairment $(p=0.73)$ and both groups differed from the subjects without ADHD $(p<0.001)$. Both groups of 
Table 2. Prevalence (95\% CI) of ADHD across several symptom cut-offs and sequential application of additional ADHD criteria $(n=4000)$

\begin{tabular}{|c|c|c|c|c|c|}
\hline & $\begin{array}{l}\text { Symptom cut-off only } \\
\text { (without additional } \\
\text { criteria) }\end{array}$ & $\begin{array}{l}\text { Symptom cut-off }+ \\
\text { symptoms in two or } \\
\text { more settings (A) }\end{array}$ & $\begin{array}{l}\text { Symptom cut-off+ } \\
\text { age of onset } \\
<12 \text { years (B) }\end{array}$ & $\begin{array}{l}\text { Symptom cut-off }+ \\
\text { at least moderate impairment } \\
(\text { score } \geqslant 2 \text { on a scale } 0-3)^{a}\end{array}$ & $\begin{array}{l}\text { Symptom cut-off }+ \\
\text { A and B }+ \text { at least } \\
\text { moderate impairment }\end{array}$ \\
\hline $\begin{array}{l}\text { At least } 2 / 9 \text { inattention symptoms or } 2 / 9 \\
\text { hyperactivity/impulsivity symptoms }\end{array}$ & $33.2(31.74-34.66)$ & $25.2(23.85-26.55)$ & $6.7(5.93-7.47)$ & $18.7(17.49-19.91)$ & $3.9(3.3-4.5)$ \\
\hline $\begin{array}{l}\text { At least } 3 / 9 \text { inattention symptoms or } 3 / 9 \\
\text { hyperactivity/impulsivity symptoms }\end{array}$ & $32.3(30.85-33.75)$ & $24.5(23.17-25.83)$ & $6.5(5.74-7.26)$ & $18.4(17.2-19.6)$ & $3.9(3.3-4.5)$ \\
\hline $\begin{array}{l}\text { At least } 4 / 9 \text { inattention symptoms or } 4 / 9 \\
\text { hyperactivity/impulsivity symptoms }\end{array}$ & $29.4(27.99-30.81)$ & $22.8(21.5-24.1)$ & $6.3(5.55-7.05)$ & $17.6(16.42-18.78)$ & $3.8(3.21-4.39)$ \\
\hline $\begin{array}{l}\text { At least } 5 / 9 \text { inattention symptoms or } 5 / 9 \\
\text { hyperactivity/impulsivity symptoms }\end{array}$ & $23.7(22.38-25.02)$ & $18.6(17.39-19.81)$ & $5.4(4.7-6.1)$ & $15.1(13.99-16.21)$ & $3.55(2.98-4.12)$ \\
\hline $\begin{array}{l}\text { At least } 6 / 9 \text { inattention symptoms or } 6 / 9 \\
\text { hyperactivity/impulsivity symptoms }\end{array}$ & $17.6(16.42-18.78)$ & $14.1(13.02-15.18)$ & $4.2(3.58-4.82)$ & $12(10.99-13.01)$ & $2.9(2.38-3.42)$ \\
\hline $\begin{array}{l}\text { At least } 7 / 9 \text { inattention symptoms or } 7 / 9 \\
\text { hyperactivity/impulsivity symptoms }\end{array}$ & 10.9 (9.93-11.87) & $9(8.11-9.89)$ & $2.6(2.11-3.09)$ & $7.9(7.06-8.74)$ & $1.9(1.48-2.32)$ \\
\hline
\end{tabular}

ADHD, Attention-deficit/hyperactivity disorder; CI, confidence interval.

a Impairment related to the ADHD symptoms.

Additional data for subjects presenting with five of nine inattentive+five of nine hyperactive/impulsive symptoms are available upon request. 
Table 3. Confirmatory factor analysis (CFA) of 18 DSM-5 ADHD symptoms with fit indexes for different models of ADHD and model comparison $(n=1329)$

\begin{tabular}{|c|c|c|c|c|c|c|c|c|c|c|}
\hline Individual models & $\mathrm{FP}$ & $\chi^{2}$ & $\mathrm{df}$ & \multicolumn{2}{|c|}{ RMSEA $(90 \% \mathrm{CI})$} & CFI & TLI & WRMR & AIC & $\mathrm{BIC}$ \\
\hline One-factor (1F) & 36 & 1312.284 & 135 & \multicolumn{2}{|c|}{$0.081(0.077-0.085)$} & 0.530 & 0.467 & 2.751 & 28299.938 & 28486.856 \\
\hline Correlated two-factor $\left(\mathrm{C}_{2 \mathrm{~F}}\right)$ & 37 & 843.561 & 134 & \multicolumn{2}{|c|}{$0.063(0.059-0.067)$} & 0.717 & 0.676 & 2.225 & 27968.951 & 28161.061 \\
\hline Correlated three-factor $\left(\mathrm{C}_{3 \mathrm{~F}}\right)$ & 39 & 820.780 & 132 & \multicolumn{2}{|c|}{$0.063(0.059-0.067)$} & 0.725 & 0.681 & 2.180 & 27935.872 & 28138.367 \\
\hline $\begin{array}{l}\text { Bifactor (one general, } \\
\text { two specific, } \mathrm{B}_{1 \mathrm{G} 2 \mathrm{~S}} \text { ) }\end{array}$ & 54 & 429.482 & 117 & \multicolumn{2}{|c|}{$0.045(0.04-0.049)$} & 0.875 & 0.837 & 1.492 & 27655.448 & 27973.256 \\
\hline $\begin{array}{l}\text { Bifactor (one general, } \\
\text { three specific) }\end{array}$ & \multicolumn{5}{|c|}{ No convergence } & & & & & \\
\hline Bifactor incomplete $\left(\mathrm{B}_{\text {inc }}\right)$ & 48 & 727.001 & 123 & \multirow{2}{*}{\multicolumn{2}{|c|}{$0.061(0.057-0.065)$}} & 0.759 & 0.700 & 1.983 & 27864.720 & 28147.216 \\
\hline Second-order two-factor & \multicolumn{3}{|c|}{ No convergence } & & & & & & & \\
\hline Second-order three-factor $\left(2_{3 \mathrm{~F}}^{\text {nd }}\right)$ & 39 & 820.780 & 132 & \multicolumn{2}{|c|}{$0.063(0.059-0.067)$} & 0.725 & 0.681 & 2.180 & 27935.819 & 28138.314 \\
\hline Model comparison & & & $\Delta \chi^{2}$ & $\mathrm{df}$ & $p$ value & $\Delta \mathrm{A}$ & & $\Delta \mathrm{BIC}$ & & \\
\hline \multicolumn{11}{|l|}{ Within correlated models } \\
\hline $1 \mathrm{~F} v \cdot \mathrm{C}_{2 \mathrm{~F}}$ & & & \multirow{2}{*}{$\begin{array}{r}179.322 \\
22.040\end{array}$} & 1 & $<0.0001$ & \multicolumn{2}{|c|}{330.99} & 325.79 & \multicolumn{2}{|c|}{$\mathrm{C}_{2 \mathrm{~F}}$ is better than $1 \mathrm{~F}$} \\
\hline $\mathrm{C}_{2 \mathrm{~F}} v \cdot \mathrm{C}_{3 \mathrm{~F}}$ & & & & 2 & $<0.0001$ & \multicolumn{2}{|c|}{33.08} & 22.69 & \multicolumn{2}{|c|}{$C_{3 F}$ is better than $C_{2 F}$} \\
\hline \multicolumn{11}{|l|}{ Within bifactor models } \\
\hline $\mathrm{B}_{1 \mathrm{G} 2 \mathrm{~S}} v \cdot \mathrm{B}_{\mathrm{inc}}$ & & & 220.024 & 6 & $<0.0001$ & -209 & & -173.96 & $\mathrm{~B}_{1 \mathrm{G} 2 \mathrm{~S}}$ is bett & er than $B_{\text {inc }}$ \\
\hline \multicolumn{11}{|l|}{ Between models with best fit } \\
\hline \multirow{2}{*}{\multicolumn{3}{|c|}{$\begin{array}{l}\mathrm{C}_{3 \mathrm{~F}} \text { (best correlated) } v . \mathrm{B}_{1 \mathrm{G} 2 \mathrm{~S}} \text { (best bifactor) } \\
\mathrm{C}_{3 \mathrm{~F}} \text { (best correlated) } v .2 \mathrm{nd}\end{array}$}} & \multirow{2}{*}{\multicolumn{2}{|c|}{305.820}} & \multirow[t]{2}{*}{$<0.0001$} & \multicolumn{2}{|c|}{280.42} & 165.11 & \multirow{2}{*}{\multicolumn{2}{|c|}{$\begin{array}{l}\mathrm{B}_{1 \mathrm{G} 2 \mathrm{~S}} \text { is better than } \mathrm{C}_{3 \mathrm{~F}} \\
\text { - }\end{array}$}} \\
\hline & & & - & & & \multirow{2}{*}{\multicolumn{2}{|c|}{-280.37}} & & & \\
\hline \multicolumn{3}{|l|}{$\mathrm{B}_{1 \mathrm{G} 2 \mathrm{~S}}$ (best bifactor) $v .2_{3 \mathrm{~F}}^{\mathrm{nd}}$} & 305.820 & 15 & $<0.0001$ & & & -165.06 & \multicolumn{2}{|c|}{$\mathrm{B}_{1 \mathrm{G} 2 \mathrm{~S}}$ is better than $2_{3 \mathrm{~F}}^{\text {nd }}$} \\
\hline
\end{tabular}

ADHD, Attention-deficit/hyperactivity disorder; FP, free parameters; df, degrees of freedom; RMSEA, root mean square error of approximation; CI, confidence interval; CFI, Comparative Fit Index; TLI, Tucker-Lewis Index; WRMR, weighted root mean square residual; AIC, Akaike information criterion; BIC, Bayesian information criterion.

Parameters were estimated using mean and variance adjusted weighted least squares (WLSMV), except for AIC and BIC, which were estimated using the robust maximum likelihood estimator (MLE). $\Delta \chi^{2}$ represents the robust chi-square difference test with mean and variance adjusted test statistics. $\triangle \mathrm{AIC}$ and $\triangle \mathrm{BIC}$ represent the difference between AIC and BIC for each model comparison: values $\geqslant 10$ indicate overwhelming support for the model with the lower AIC and BIC values. Bold values indicate the model that provided the best fit for the data.

cases also presented similar male/female ratios (39.3\% versus $40 \%$ ) and rates of co-morbidity with anxiety disorders (37.1\% and 40\%). However, new cases identified only by DSM-5 had a higher prevalence of co-morbid mood disorders (16\% and $7.7 \%)$.

\section{Assessment of the factor solution that provides the best fit for ADHD symptoms}

The data fit indexes for several factorial models tested in CFA are presented in Table 3. The model with the best factor structure for DSM-5 symptoms was the bifactor model with one general factor and two specific factors (RMSEA 0.045, 90\% CI 0.040-0.049; CFI 0.875; TLI 0.837; WRMR 1.492). The most important implication from these findings is that a general factor substantially influences all of the ADHD symptoms whereas the specific factors account for additional variance related to inattention and hyperactivity/ impulsivity.

\section{Assessment of the association of ADHD symptoms with clinical impairment}

The results for the performance of the 18 DSM- 5 symptoms in predicting moderate to severe clinical impairment are presented in Table 4. According to the unadjusted OR ranking, there were four inattention symptoms among the top-five predicting items. In the conventional logistic regression analysis, seven symptoms (five inattention and two hyperactivity items) remained as independent predictors of clinical impairment (adjusted $R^{2}=0.123$ ). In the APS regression, five inattention ('Difficulty sustaining attention', 'Difficulty organizing tasks', 'Easily distracted', 'Loses objects', 'Fails to give close attention to details') and only two hyperactivity symptoms ('On the go', 
Table 4. Association of individual DSM-5 ADHD symptoms with clinical impairment ( $n=1329)$

\begin{tabular}{|c|c|c|c|c|c|c|}
\hline \multirow[b]{2}{*}{ DSM-5 symptoms } & \multicolumn{2}{|l|}{ Endorsement (\%) } & \multicolumn{4}{|c|}{$\begin{array}{l}\text { Association with at least moderate clinical } \\
\text { impairment }^{\mathrm{a}} \text { (score } \geqslant 2 \text {, scale } 0-3 \text { ) }\end{array}$} \\
\hline & $\begin{array}{l}\text { Screening positive } \\
\text { subjects (1329) }\end{array}$ & $\begin{array}{l}\text { ADHD } \\
\text { cases (142) }\end{array}$ & $\begin{array}{l}\text { Unadjusted } \\
\text { OR }(95 \% \mathrm{CI})\end{array}$ & $\begin{array}{l}\text { Unadjusted } \\
\text { OR ranking }\end{array}$ & $\begin{array}{l}\text { Adjusted } \\
\text { OR }(95 \% \mathrm{CI})\end{array}$ & APS \\
\hline $\begin{array}{l}\text { 01. Fails to give close attention } \\
\text { to details }\end{array}$ & 67.2 & 75.4 & $1.73(1.37-2.18)$ & 6 & $1.36(1.07-1.75)$ & 6 \\
\hline $\begin{array}{l}\text { 02. Difficulty sustaining } \\
\text { attention }\end{array}$ & 64.9 & 83.1 & $2.06(1.63-2.59)$ & 2 & $1.52(1.18-1.94)$ & 10 \\
\hline 03. Does not seem to listen & 49.1 & 60.6 & $1.82(1.46-2.27)$ & 5 & N.s. & 3 \\
\hline 04. Does not follow through & 46 & 56.3 & $1.73(1.39-2.16)$ & 6 & N.S. & 4 \\
\hline 05. Difficulty organizing tasks & 49.8 & 64.8 & $1.83(1.47-2.28)$ & 4 & $1.66(1.31-2.09)$ & 10 \\
\hline $\begin{array}{l}\text { 06. Reluctant to engage in } \\
\text { 'mental' tasks }\end{array}$ & 75.3 & 81.7 & $1.30(1.01-1.66)$ & 14 & N.S. & 0 \\
\hline 07. Loses objects & 30.2 & 43 & $1.61(1.26-2.04)$ & 9 & $1.41(1.09-1.82)$ & 8 \\
\hline 08. Easily distracted & 81.7 & 90.1 & $2.51(1.89-3.35)$ & 1 & $2.13(1.58-2.87)$ & 10 \\
\hline 09. Forgetful & 61.1 & 68.3 & $1.37(1.09-1.71)$ & 11 & N.S. & 0 \\
\hline 10. Fidgets & 83.1 & 86.6 & $0.90(0.67-1.20)$ & N.s. & N.S. & 1 \\
\hline 11. Gets up & 34.4 & 52.8 & $1.88(1.49-2.38)$ & 3 & $1.43(1.11-1.84)$ & 6 \\
\hline 12. Runs about & 56.5 & 73.9 & $1.64(1.32-2.04)$ & 8 & N.s. & 2 \\
\hline 13. Excessively loud & 38.8 & 48.6 & $1.28(1.02-1.60)$ & 15 & N.S. & 0 \\
\hline 14. On the go & 31.6 & 53.5 & $1.57(1.24-1.99)$ & 10 & $1.47(1.14-1.89)$ & 10 \\
\hline 15. Talks excessively & 30.5 & 36.6 & $1.35(1.07-1.72)$ & 12 & N.S. & 0 \\
\hline 16. Blurts out answers & 31.6 & 43.7 & $1.28(1.01-1.62)$ & 15 & N.S. & 0 \\
\hline 17. Difficulty waiting his turn & 39.4 & 45.1 & $1.31(1.06-1.64)$ & 13 & N.s. & 0 \\
\hline 18. Interrupts or intrudes & 9.2 & 12.7 & $1.31(0.89-1.92)$ & N.s. & N.S. & 0 \\
\hline
\end{tabular}

ADHD, Attention-deficit/hyperactivity disorder; OR, odds ratio; CI, confidence interval; APS, all possible subsets; N.s., non-significant association between ADHD symptom and clinical impairment.

These analyses were performed only for the 1329 subjects who screened positive for ADHD (at least two positive screening questions) and provided information on all 18 ADHD symptoms. Bold values indicate the 7 symptoms that were more consistent across the top-10 ranked subsets of $n=7$ symptoms in APS regression. According to this criterion, these highlighted symptoms would be the best predictors of impairment.

${ }^{a}$ Impairment related to the ADHD symptoms. Unadjusted ORs from the $\chi^{2}$ test. Adjusted ORs from conventional binary regression analysis. APS results display the number of times the symptoms appear among the top-10 ranked subsets of seven symptoms (according to general $\chi^{2}$ ).

'Gets up') were present in more than half of the top-10 subsets of seven symptoms. In all the analyses, inattention items performed better than hyperactivity/impulsivity items in predicting clinical impairment.

\section{Assessment of the best number of ADHD symptoms (cut-off point) to identify clinical impairment}

ROC analyses were performed with both inattention and hyperactivity/impulsivity symptoms, considering the presence of moderate to severe clinical impairment as the gold standard. In the model including subjects with no positive symptoms in the screening instrument, the best inattention cut-off for predicting clinical impairment was four symptoms [sensitivity 88\% and specificity $70.9 \%$; area under the curve (AUC) for the ROC analysis $0.860,95 \%$ CI $0.845-0.875]$. For hyperactivity/impulsivity, the best cut-off was one symptom (sensitivity $96 \%$ and specificity 61\%; AUC $0.819,95 \%$ CI $0.802-0.837)$. When only the ADHD screening positive subjects were included, the best inattention cut-off for predicting clinical impairment was five symptoms (sensitivity $73.4 \%$ and specificity 49.8\%; AUC 0.658, 95\% CI 0.629-0.688). For hyperactivity/impulsivity, the best cut-off was four symptoms (sensitivity $54.2 \%$ and specificity $61.4 \%$; AUC $0.588,95 \%$ CI $0.558-0.619$ ). The sensitivity and specificity for other cut-off points are available upon request.

\section{Discussion}

As far as we are aware, this is the first comprehensive evaluation of DSM-5 ADHD criteria in a large, representative, population-based sample of adult subjects. In general, our results suggest that the new DSM-5 
ADHD criteria would determine a $27 \%$ increase in the prevalence rate of ADHD, compared with DSM-IV criteria $(3.55 \%$ v. $2.8 \%)$. However, the new criteria did not impact substantially on the factor structure of the disorder. In addition, our data support previous DSM-IV findings suggesting that inattentive symptoms are core in the ADHD diagnostic definition in adults, and that there are potential benefits in lowering the symptomatic threshold for diagnosing ADHD in adults.

Our clinical and sociodemographic data concur with previous findings. The developmental decrease in hyperactive symptoms determines that ADHD inattentive is often the most frequent clinical presentation seen in clinical and epidemiological samples of adults (Grevet et al. 2006; Barkley, 2010). Although Kessler et al. (2006) have found a male/female ratio of around 1.6, previous studies in adults did not find consistent gender effects, as seen in children (Kooij et al. 2005). As in our study, a preponderance of females was detected when the DSM-IV symptomatic cut-off was reduced from $6 / 9$ to $4 / 9$ in a population study in The Netherlands (Kooij et al. 2005). Our co-morbidity rates with anxiety and mood disorder were lower than those detected by Kessler et al. (2005), probably reflecting the fact that we assessed young adults differently; the study by Kessler et al. assessed individuals up to 44 years of age. Although the lack of significant difference in academic achievement between cases and subjects without ADHD in our study might reflect the young age of the adults assessed, Kessler et al. (2005) also did not find a significant difference in education in the National Comorbidity Survey Replication (NCS-R). However, other studies have found a lower academic achievement for subjects with ADHD (e.g. Ebejer et al. 2012).

When all additional criteria (symptom pervasiveness, age at onset before age 12 years, and moderate/ severe impairment) besides symptom threshold were used, the prevalence of ADHD ranged from 2.9\% (with a cut-off of six symptoms in any dimension) to $3.8 \%$ (with a four-symptom cut-off). These prevalence rates are not very different from the rates found in previous DSM-IV-based population studies in the USA. A telephone survey of 966 adults (Faraone \& Biederman, 2005) found a $2.9 \%$ prevalence of ADHD. A rate of ADHD of $4.4 \%$ was reported in a US nationally representative household survey with 3199 adults (Kessler et al. 2006). International estimates of ADHD prevalence in adults were also in the same range (Simon et al. 2009). In a comprehensive assessment in 10 different countries with 11422 adults, a mathematical model of multiple imputations was used to derive a pooled ADHD prevalence of $3.4 \%$ (Fayyad et al. 2007). However, lower prevalence rates have been found in some studies (Kooij et al. 2005; MedinaMora et al. 2005; Ebejer et al. 2012). These lower rates are closer to the rates that our study found when severe impairment was required as an additional criterion for ADHD (1.4\%). Because of differences in methodology, comparisons among different prevalence studies are always difficult (see Polanczyk et al. 2007). The relevant issue here is that, by using the same methodology and in the same sample, we found an estimated increase of $27 \%$ in the prevalence rate of ADHD on going from DSM-IV to DSM-5. It is important to note that ADHD cases by the definition assumed in this study reported at least moderate impairment caused by the symptoms, independently of the diagnostic system used. In addition, ADHD cases defined only by DSM- 5 did not present a significantly different impairment score than those identified by both DSM versions. Thus, DSM-5 criteria might be extending the diagnosis to people suffering with the disorder who were not assigned a place in the classification system according to the previous DSM-IV. Future studies need to address how to decide where to put the diagnostic threshold in dimensional disorders such as ADHD, where investigations have been documenting for a long time that the linear increase in symptoms seems to determine augmentation of impairment (Fergusson et al. 1997).

Our results also underscore the importance of addressing all ADHD criteria, not just symptom count. In particular, the impact of applying the DSM-5 age-at-onset criterion on reducing ADHD prevalence is relevant: considering only a five-symptom cut-off in any dimension, the ADHD endorsement rate would be $23.7 \%$ (95\% CI 22.38-25.02). Adding the age-at-onset criterion alone (without other additional criteria) would decrease this rate to $5.4 \%$ (95\% CI 4.7-6.1). As expected, a similar result emerged for the impairment criterion: adding the moderate impairment criterion alone would increase the endorsement rate to $15.1 \%$ (95\% CI 13.99-16.21). These additional criteria were more relevant for making the prevalence closer to the one expected than any potential variations in symptom cut-off criterion. Taken together, these results might serve as clinical rationale for emphasizing the importance of carefully addressing ADHD additional criteria (especially age at onset and impairment) during the diagnostic evaluation.

CFAs with the DSM-5 symptoms found a bifactor model with one general and two specific factors as the best fit for the data. A bifactor model was also the best fit in many DSM-IV-based previous studies (Dumenci et al. 2004; Toplak et al. 2009, 2012; Martel et al. 2010, 2011; Gibbins et al. 2012; Normand et al. 2012; Ullebø et al. 2012), suggesting that the proposed rewording and new clinical examples would not 
change the expected factorial structure of ADHD symptoms. This model is in line with multiple pathway conceptions of the disorder (Nigg et al. 2005) and better explains symptomatic overlap/distinctiveness and stability/change, accounting more clearly for disorder heterogeneity.

Regarding the performance of DSM-5 symptoms in predicting ADHD-related impairment, the three-step approach yielded consistent results, suggesting that inattention symptoms, as a group, are more closely associated with impairment than hyperactivity/impulsivity symptoms. This pattern does not seem to be influenced by a higher endorsement rate for inattention symptoms. If we rank the 18 ADHD symptoms according to their frequency in ADHD patients, the seven symptoms significantly associated with impairment are ranked as follows: 1st, 3rd, 5th, 8th, 11th, 12th and 16th. Thus, it does not seem that those significantly associated with impairment were only distributed in the first ranks of frequency. To analyze this issue statistically, we assessed the correlation of the 18 symptom ranks in terms of frequency with their ranks in terms of the number of times they appeared as part of the top-10 subsets of seven symptoms predicting impairment in APS analyses. No significant association was found $(p>0.10)$. These results stress the relevance of inattention as a predictor of clinical impairment in adults. Although the specific list varies across studies, inattentive symptoms as a group are usually reported as the best predictors of ADHD-related impairment in previous investigations. Barkley et al. (2008) reported that the five ADHD symptoms with the strongest associations with the presence of any impairment were inattentive symptoms. A population-based study by Das et al. (2012) also documented that inattentive symptoms were the most strongly associated with clinical impairment.

Our ROC analyses, independently of the strategy used, found that a lower symptom threshold than the one proposed by DSM-IV determined the best balance between sensitivity and specificity for predicting at least moderate impairment for both inattention and hyperactivity/impulsivity dimensions. These findings concur with previous DSM-IV-based studies suggesting that a lower threshold of symptoms might be adequate in adult ADHD samples (Murphy \& Barkley, 1996; Solanto et al. 2012). Kooij et al. (2005) reported that subjects with four or more DSM-IV symptoms in any ADHD dimension were significantly more impaired than subjects with fewer symptoms in a large, population-based sample in The Netherlands. Moreover, an investigation by Hoogman et al. (2012) suggested similar brain volumetric measures in adults presenting with a lower symptom threshold of four symptoms and subjects with six or more symptoms in any ADHD dimension. Both groups differed from those with fewer ADHD inattentive or hyperactive/impulsive symptoms.

Our study has some strengths and also methodological limitations related to logistic issues. To the best of our knowledge, this is the first population study assessing DSM-5 ADHD criteria. We assessed young adults, and all previous DSM-IV and DSM-5 field trials in adults have not addressed ADHD. Our data were derived from a large, representative, population-based sample. Finally, we implemented assessment methods that could mimic clinical assessment in the real world, as far as possible in an epidemiological investigation. Regarding limitations, our subjects were all 18-19 years old and our data might not be fully generalized to older adults. Our diagnostic process was performed only with the subjects and did not aggregate information from significant others, a strategy that could have minimized the risk of under-reporting ADHD symptoms, and might have improved the reliability of our retrospective assessment of ADHD symptoms before age 12. Our impairment measure was based only on the subject's perspective; a rater-derived score based on functional correlates was not used. It is important to bear in mind that previous investigations have found high agreement between self and parent information for ADHD diagnosis in adults (see Murphy \& Schachar, 2000), and clinicians tend to see young adult patients without parents and to rely on self-perception about impairment more than on scales. Thus, we are confident that our strategy of assessment adequately mimics the scenario seen in a clinical setting. However, our data are probably more applicable to scenarios where diagnosis relies on self-report. We could not assess some important ADHD co-morbidities, such as other externalizing disorders, anti-social personality disorder or substance-use disorder. Moreover, we used a screening tool for ADHD, and 2671 subjects (66.8\% of the total sample) presented a negative screening for the disorder and therefore answered only the six screening questions. This high proportion of screeningnegative subjects posed some difficulties to our data analyses. Those analyses that required information about individual symptoms (CFA, association between individual symptoms and impairment) had to be performed only with the subsample that screened positive and provided complete information about all ADHD symptoms $(n=1329)$. For our prevalence assessment, we assumed that those who screened negative for ADHD did not have the disorder. This assumption allowed us to assess the prevalence of ADHD for the entire population sample, but it is theoretically possible (although clinically unlikely) that our approach missed some ADHD cases. To deal with this possibility, we performed a mathematical modeling for imputing data 
for the 1833 subjects who had only one screening positive symptom based on the patterns of response of those that had two screening positive symptoms and therefore provided information on all 18 symptoms (data available upon request). The prevalence rate found was slightly higher, as expected (3.9\%, 95\% CI 3.3-4.5). Finally, the AUC for our ROC analyses when only the ADHD screening positive subsample was included showed a diagnostic performance substantially lower than that detected when the entire sample was considered (i.e. individuals in the lower extreme of the symptomatic presentation are not excluded). In other words, these analyses are more likely to reflect the clinical reality of differentiating clinical cases from those with some level of symptoms including subthreshold cases.

Overall, our findings suggest that the DSM-5 changes in ADHD criteria determine a $27 \%$ increase in ADHD prevalence rates in adults, even when all diagnostic criteria (particularly age-at-onset and impairment criteria) are included in the evaluation process. The results reinforce the notion that using new wording and clinical examples would not change either the expected factorial structure of ADHD symptoms or the stronger association between inattention and clinical impairment found in adults. Moreover, our study reinforces the view that a lower cut-off point for the number of inattentive and/or hyperactive/impulsive symptoms is more suitable for adult patients.

\section{Acknowledgments}

This work was partially supported by research grants from: the National Council for Scientific and Technological Development (CNPq, Brazil) and the Hospital de Clinicas de Porto Alegre (HCPA), Porto Alegre, Brazil. E. H. Grevet received a governmental $\mathrm{CNPq}$ post-doctoral fellowship and C. Kieling and G. A. Salum received governmental CAPES/ FAPERGS post-doctoral fellowships. The Welcome Trust supports the Pelotas Birth Cohort Study. The European Union and the Brazilian National Program for Centers of Excellence (PRONEX-CNPq) funded the initial phases of the study.

\section{Declaration of Interest}

L. A. Rohde was on the speakers' bureau/advisory board and/or acted as consultant for Eli-Lilly, Janssen-Cilag, Novartis and Shire in the past 3 years. The ADHD and Juvenile Bipolar Disorder Out-patient Programs chaired by L. A. Rohde received unrestricted educational and research support from the following pharmaceutical companies in the past 3 years: EliLilly, Janssen-Cilag, Novartis and Shire. He receives authorship royalties from Oxford Press and ArtMed. He has also received travel awards for taking part in the 2014 APA meeting from Shire. C. Kieling took part in two meetings on ADHD sponsored by Novartis and Shire in 2010 and 2011 and in a meeting on the promotion of editorial capacity among editors from low-income and middle-income countries sponsored by Deva in 2010. E. H. Grevet was on the speakers' bureau for Shire in the past 3 years and took part in one meeting on ADHD sponsored by Shire in 2014.

\section{References}

Amorim P (2003). The Mini Neuropsychiatric Interview (MINI): validation of a short structured diagnostic psychiatric interview. Revista Brasileira de Psiquiatria 22, 26-39.

APA (2013). Diagnostic and Statistical Manual of Mental Disorders, Fifth Edition. DSM-5. American Psychiatric Association: Washington, DC.

Asparouhov T, Muthén B (2006). Robust Chi Square Difference Testing with mean and variance adjusted test statistics. Mplus Web Notes: No. 10.

Barkley RA (2010). Attention Deficit Hyperactivity Disorder in Adults. Jones \& Bartlett Publishers: Sudbury, MA.

Barkley RA, Murphy KR, Fischer M (2008). ADHD in Adults: What the Science Says. Guilford Press: New York, NY.

Batstra L, Frances A (2012). DSM-5 further inflates attention deficit hyperactivity disorder. Journal of Nervous and Mental Disease 200, 486-488.

Burnham KPAD (2004). Multimodel inference: understanding AIC and BIC in model selection. Sociological Methods and Research 33, 261-304.

Das D, Cherbuin N, Butterworth P, Anstey KJ, Easteal S (2012). A population-based study of attention deficit/ hyperactivity disorder symptoms and associated impairment in middle-aged adults. PLoS One 7, e31500.

Dumenci L, McConaghy SH, Achenbahj TM (2004). A hierarchical three-factor model of inattention-hyperactivity-impulsivity derived from the attention problems syndrome of the teacher's report form. School Psychology Review 33, 287-301.

Ebejer JL, Medland SE, van der Werf J, Gondro C, Henders AK, Lynskey M, Martin NG, Duffy DL (2012). Attention deficit hyperactivity disorder in Australian adults: prevalence, persistence, conduct problems and disadvantage. PLoS One 7, e47404.

Faraone SV, Biederman J (2005). What is the prevalence of adult ADHD? Results of a population screen of 966 adults. Journal of Attention Disorders 9, 384-391.

Faraone SV, Biederman J, Spencer T, Mick E, Murray K, Petty C, Adamson JJ, Monuteaux MC (2006). Diagnosing adult attention deficit hyperactivity disorder: are late onset and subthreshold diagnoses valid? American Journal of Psychiatry 163, 1720-1729.

Fayyad J, de Graaf R, Kessler RC, Alonso J, Angermeyer M, Demyttenaere K, de Girolamo G, Haro JM, Karam EG, Lara C, Lepine JP, Ormel J, Posada-Villa J, Zaslavsky AM, Jin R (2007). Cross-national prevalence and correlates of 
adult attention-deficit hyperactivity disorder. British Journal of Psychiatry 190, 402-409.

Fergusson DM, Lynskey MT, Horwood LJ (1997).

Attentional difficulties in middle childhood and psychosocial outcomes in young adulthood. Journal of Child Psychology and Psychiatry 38, 633-644.

Gibbins C, Toplak Me, Flora DB, Weiss MD, Tannock R (2012). Evidence for a general factor model of ADHD in adults. Journal of Attention Disorders 16, 635-644.

Goodman SH, Lahey BB, Fielding B, Dulcan M, Narrow W, Regier D (1997). Representativeness of clinical samples of youths with mental disorders: a preliminary populationbased study. Journal of Abnormal Psychology 106, 3-14.

Grevet EH, Bau CH, Salgado CA, Fischer AG, Kalil K, Victor MM, Garcia CR, Sousa NO, Rohde LA, Belmonte-de-Abreu P (2006). Lack of gender effects on subtype outcomes in adults with attention-deficit/ hyperactivity disorder: support for the validity of subtypes. European Archives of Psychiatry and Clinical Neuroscience 256, 311-319.

Hoogman M, Rijpkema M, Janss L, Brunner $H$, Fernandez G, Buistelaar J, Franke B, Arias-Vásquez A (2012). Current self-reported symptoms of attention deficit/ hyperactivity disorder are associated with total brain volume in healthy adults. PLoS One 7, e31273.

Hu L, Bentler PM (1999). Cutoff criteria for fit indexes in covariance structure analysis: conventional criteria versus new alternatives. Structural Equation Modeling 6, 1-55.

Jablensky A (2012). Prototypes, syndromes and dimensions of psychopathology: an open agenda for research. World Psychiatry 11, 22-23.

Kessler RC, Adler L, Ames M, Demler O, Faraone S, Hiripi E, Howes MJ, Jin R, Secnik K, Spencer T, Ustun TB, Walters EE (2005). The World Health Organization Adult ADHD Self-Report Scale (ASRS): a short screening scale for use in the general population. Psychological Medicine 35, 245-256.

Kessler RC, Adler L, Barkley R, Biederman J, Conners CK, Demler O, Faraone SV, Greenhill LL, Howes MJ, Secnik K, Spencer T, Üstün TB, Walters EE, Zaslavsky AM (2006). The prevalence and correlates of adult ADHD in the United States: results from the National Comorbidity Survey Replication. American Journal of Psychiatry 163, 716-723.

Kessler RC, Green JG, Adler LA, Barkley RA, Chatterji S, Faraone SV, Finkelman M, Greenhill LL, Gruber MJ, Jewell M, Russo LJ, Sampson NA, Van Brunt DL (2010). Structure and diagnosis of adult attention-deficit/ hyperactivity disorder: analysis of expanded symptom criteria from the Adult ADHD Clinical Diagnostic Scale. Archives of General Psychiatry 67, 1168-1178.

Kooij JJ, Buitelaar JK, van den Oord EJ, Furer JW, Rijnders CA, Hodiamont PP (2005). Internal and external validity of attention-deficit hyperactivity disorder in a population-based sample of adults. Psychological Medicine $35,817-827$.

Maj M (2011). Psychiatric diagnosis: pros and cons of prototype vs. operational criteria. World Psychiatry 10, $81-82$.
Marques JMA, Zuardi AW (2008). Validity and applicability of the Mini International Neuropsychiatric Interview administered by family medicine residents in primary health care in Brazil. General Hospital Psychiatry 30, 303-310.

Martel MM, Roberts B, Gremillion M, von Eye A, Nigg JT (2011). External validation of bifactor model of ADHD: explaining heterogeneity in psychiatric comorbidity, cognitive control, and personality trait profiles within DSM-IV ADHD. Journal of Abnormal Child Psychology 39, 1111-1123.

Martel MM, von Eye A, Nigg JT (2010). Revisiting the latent structure of ADHD: is there a ' $\mathrm{g}$ ' factor? Journal of Child Psychology and Psychiatry 51, 905-914.

Matte B, Rohde LA, Grevet EH (2012). ADHD in adults: a concept in evolution. Attention Deficit and Hyperactivity Disorders 4, 53-62.

Medina-Mora ME, Borges G, Lara C, Benjet C, Blanco J, Fleiz C, Villatoro J, Rojas E, Zambrano J (2005). Prevalence, service use, and demographic correlates of 12-month DSM-IV psychiatric disorders in Mexico: results from the Mexican National Comorbidity Survey. Psychological Medicine 35, 1773-1783.

Murphy K, Barkley RA (1996). Prevalence of DSM-IV symptoms of ADHD in adult licensed drivers: implications for clinical diagnosis. Journal of Attention Disorders 1, 147-161.

Murphy P, Schachar R (2000). Use of self-ratings in the assessment of symptoms of attention deficit hyperactivity disorder in adults. American Journal of Psychiatry 157, 1156-1159.

Muthén LK, Muthén BO (2012). Mplus User's Guide. Muthén \& Muthén: Los Angeles, CA.

Nigg JT, Willcutt EG, Doyle AE, Sonuga-Barke EJ (2005). Causal heterogeneity in attention-deficit/hyperactivity disorder: do we need neuropsychologically impaired subtypes? Biological Psychiatry 57, 1224-1230.

Normand S, Flora DB, Toplak ME, Tannock R (2012). Evidence for a general ADHD factor from a longitudinal general school population study. Journal of Abnormal Child Psychology 40, 555-567.

Polanczyk G, Caspi A, Houts R, Kollins SH, Rohde LA, Moffitt TE (2010). Implications of extending the ADHD age-of-onset criterion to age 12: results from a prospectively studied birth cohort. Journal of the American Academy of Child and Adolescent Psychiatry 49, 210-216.

Polanczyk G, de Lima MS, Horta BL, Biederman J, Rohde LA (2007). The worldwide prevalence of ADHD: a systematic review and metaregression analysis. American Journal of Psychiatry 164, 942-948.

Regier DA, Narrow WE, Clarke DE, Kraemer HC, Kuramoto SJ, Kuhl EA, Kupfer DJ (2013). DSM-5 field trials in the United States and Canada, Part II: Test-retest reliability of selected categorical diagnoses. American Journal of Psychiatry 170, 59-70.

Rösler M, Retz W, Thome J, Schneider M, Stieglitz RD, Falkai P (2006). Psychopathological rating scales for diagnostic use in adults with attention-deficit/hyperactivity disorder (ADHD). European Archives of Psychiatry and Clinical Neuroscience 256 (Suppl. 1), i3-i11. 
Simon V, Czobor P, Bálint S, Mészáros A, Bitter I (2009). Prevalence and correlates of adult attention-deficit hyperactivity disorder: meta-analysis. British Journal of Psychiatry 194, 204-211.

Solanto MV, Marks DJ, Wasserstein J, Mitchell KJ (2012). Diagnosis of ADHD in adults: what is the appropriate DSM-5 symptom threshold for hyperactivity-impulsivity? Journal of Attention Disorders 16, 631-634.

Toplak ME, Pitch A, Flora DB, Iwenofu L, Ghelani K, Jain U, Tannock R (2009). The unity and diversity of inattention and hyperactivity/impulsivity in ADHD: evidence for a general factor with separable dimensions. Journal of Abnormal Child Psychology 37, 1137-1150.

Toplak ME, Sorge GB, Flora DB, Chen W, Banaschewski T, Buitelaar J, Ebstein R, Eisenberg J, Franke B, Gill M, Miranda A, Oades RD, Roeyers H, Rothenberger A, Sergeant J, Sonuga-Barke E, Steinhausen HC,
Thompson M, Tannock R, Asherson P, Faraone SV (2012). The hierarchical factor model of ADHD: invariant across age and national groupings? Journal of Child Psychology and Psychiatry 53, 292-303.

Ullebø AK, Breivik K, Gillberg C, Lundervold AJ, Posserud MB (2012). The factor structure of ADHD in a general population of primary school children. Journal of Child Psychology and Psychiatry 53, 927-936.

Victora CG, Hallal PC, Araújo CL, Menezes AM, Wells JC, Barros FC (2008). Cohort profile: the 1993 Pelotas (Brazil) birth cohort study. International Journal of Epidemiology 37, 704-709.

Wilcutt EG, Nigg JT, Pennington BF, Solanto MV, Rohde LA, Tannock R, Loo SK, Carlson CL, McBurnett K, Lahey BB (2012). Validity of DSM-IV attention deficit/ hyperactivity disorder symptom dimensions and subtypes. Journal of Abnormal Psychology 121, 991-1010. 